\title{
Mathematical model for determining the effect of government policies on Nigerians' standard of living and the achievement of economic comfort in Nigeria
}

\author{
Ogwumu, David. O; James Friday. E \\ Department of Mathematics and Statistics, Federal University Wukari, P.M.B 1020, Wukari - Taraba State, Nigeria
}

Email address:

onahdavid2010@gmail.com (D. Onah), chatwitfrayoo@yahoo.com (F. James)

\section{To cite this article:}

Ogwumu, David. O; James Friday. E. Mathematical Model for Determining the Effect of Government Policies on Nigerians' Standard of Living and the Achievement of Economic Comfort in Nigeria. American Journal of Applied Mathematics. Vol. 1, No. 4, 2013 , pp. 84-91. doi: $10.11648 /$ j.ajam.20130104.17

\begin{abstract}
The research is concerned with the development of a mathematical model for determining the Effect of Government Policies on Nigerians' Standard of Living which when not properly handled in turn could hamper the economic comfort of the country at large. The model was validated and observations about the model's results and the questionnaire data (before and after the introduction of government financial policies, $\mathrm{g}_{\mathrm{p}}$ ) were compared. Thereafter, the results of the comparison were analyzed using suitable statistical tools. The findings from the comparisons showed that government sudden financial policies take/reduce up to approximately $10 \%$ of the citizen's standard of living and income. Likewise, the results from our model and the questionnaire data have a higher degree of correlation which thus recommending the model as a standard measure for estimating the effect of Government Financial Policies on Nigerians' Standard of Living.
\end{abstract}

Keywords: Constraint, Duallizing, Government Parameter, Langrage’s Multiplier, Least Squares, Saddle-Point, Optimizing

\section{Introduction}

In some countries particularly Nigeria, there are so many government policies such as fuel subsidy removal, chasing of hawkers away from roads in the name of "duallizing" or constructing public/government roads, dispossessing rural dwellers of their landed properties in an attempt to bring a state capital city to an area, sudden increase in the rate of value added tax (VAT) on telecommunication services, mandating some states to implement the country's minimum wage which indirectly could cause some states to prune down the number of workers to the size they could pay, merging of Commercial Banks leading to reduction in labour force and many more.

When these policies are made, the citizens at the receiving end take to several acts of violence which in turn create situations of unrest and insecurities. However, the persistent probing and demonstrations of the citizens over these issues above prompted the researcher to swing into action and investigate whether there is actually any relationship between government sudden policies and the standard of living of Nigerians. Thus, the outcome of the researcher's investigation was what gave birth to this work. Meanwhile, this work is a follow-up of the researcher [8] perception that government policies have a lot to do in bringing about a stable standard of living to her citizens. As he recommended that government policies should be made to enhance judicious use of the Nation's poverty alleviation programme and supports in order to achieve the vision 20; 2020 which is a domesticated version of the MDGs in Nigeria [7, 5].

A question may be asked, what is this standard of living? The standard of living includes factors such as income, quality and availability of employment, class disparity, poverty rate, quality and affordability of housing, hours of work required to purchase necessities, gross domestic product, inflation rate, number of vacation days per year, affordable (or free) access to quality healthcare, quality and availability of education, life expectancy, incidence of disease, cost of goods and services, infrastructure, national economic growth, economic and political stability, political and religious freedom, environmental quality, climate and safety. Summarily, the standard of living is closely linked to 
quality of life [9].

Meanwhile, according to a scholar, mathematics is the prime instruction for understanding and explaining Technological and Scientific Economy and social world [3].Since several researchers have confirmed the indispensable role of Mathematics in national building, then the choice of addressing national developmental issue using the concept of mathematics and mathematical modelling in specific, cannot be said to be out of place.

\subsection{Relevance of the Research Work over the Existing Ones}

1. National Bureau of Statistics (NBS) produced an individual Nigerian's Standard of Living result according to Yemi (2012), the Statistician General of the federation in a Press briefing classifying in their result Nigerian into (a) Food poverty (b) Absolute poverty and (c) Relative poverty categories using questionnaire and Voice-of-thepeople approach. But the agency did not implore the use of mathematical modeling approach in their research. Meanwhile, the unique thing about this research is that, it adopted the use of mathematical modeling approach which gives room for comparison of methods and findings.

2. Ogwumu e.tal (2013b) developed a mathematical Model for estimating Nigerian's Standard of Living. But he did not consider the effect of Government policy Parameter on an individual's Standard of living as evident in this our research.

\subsection{Limitation of the Research and Suggestions for Further Studies}

The questionnaire data used for the proposed Nigerians' standard of living model in the equation (3.16) utilized by this work was gathered based on a purposeful sampling technique due to resources and time limitations. Whereas, for such a research as that, in order to obtain a data that is a complete representation of the Standard of Living of the entire Nigerian populace, random sampling technique (where every person in all the states of the country has equal chance in the sample) is suitable to be adopted. Hence, it is recommended that further studies be carried out on this work using questionnaire data that covers all the states in Nigeria.

\section{Main Body/Materials and Method}

\subsection{Formulation of Model Equations}

\subsubsection{Some Basic Assumptions}

To develop the research model equation, all possible parameters associated with the measurement of the standard of living will be outlined. However, while some are very important others can be ignored. Thus, the ones in the frontline are mainly considered before the negligible ones are done away with accordingly. These parameters are as discussed in the next section.

\subsubsection{Definition of Parameters/Notations}

1. The government parameter/ government policy parameter $\left(\mathrm{g}_{\mathrm{p}}\right)$ :

These government policies can be those made by federal, state, or local government. These policies could be at times innocent and of good intention to the citizens. But no matter how of good intentioned they might be, if no back up plans are made to address the people at the receiving end of the policies, so many other problems would have been created than the ones we attempt to solve.

2. Monthly income (I): this is the total earning of a family per month expressed as,

$$
I=\frac{v(1+a r)(1+b)}{f}
$$

Where $\mathrm{v}=$ the amount of earnings of the principal (basic) worker of the family

$\mathrm{a}=$ the ratio between the amount of earnings of the principal and secondary workers in the family.

$r=$ the amount earned by other working members of the family

$b=$ the ratio of other incomes of the family to the total earnings of the family

$\mathrm{f}=$ Family size. As by, [1]

1. Total Expenditures (E): total money spent per month by a family.

2. Social status/Position of the man q, (in percent): is the position a man occupies in the society which he works to maintain and working harder increases his standard of living as a result.

3. The man's societal expectation $p$,(in percent): is the expectation of a society from a man which increases as his standard of living rises and therefore makes him to work harder to keep the standard and not let the society down

4. Family size (F): this is the total persons that make up a household.

5. Standard of living parameter (S): it refers to the level of comfort, wealth, happiness, material goods and necessities available to a household in a certain socioeconomic class in a certain geographic area.

Let $T=\frac{(\text { social status or position of the man }+ \text { societal Expectatio ns from the man })}{2}$ 


$$
T=\frac{(\mathrm{q}+\mathrm{p})}{2}
$$

The equation (2.1) is formed by finding the average of the two variables $p$ and $q$ this way because; the two variables are closely related.

$>$ Also as $\mathrm{p}$ is the expectation of a society from a man which increases as his standard of living rises and therefore makes him to work harder to keep the standard and not let the society down, also $\mathrm{q}$ is the position a man occupies in the society which he works to maintain (his position) and working harder increases his standard of living; then, the man's standard of living is directly proportional to $\mathrm{T}$. Which means,

$$
S \propto T, \mathrm{~S}=\mathrm{K}_{1} \mathrm{~T}
$$

Where $K_{1}=$ constant of proportionality

$>$ A man's standard of living increases as his level of income I, increases. Hence,

$$
S=K_{2} I
$$

Where $K_{2}=$ constant of proportionality

$>\quad$ When one's level of expenditure, E increases, his standard of living decreases. Hence,

$$
S \propto \frac{1}{E} ; S=\frac{K_{3}}{E}
$$

Family size, $\mathrm{F}$ at the end of expenditure is a natural factor that affects one's standard of living indirectly as it increases as the man's standard of living is reducing. This is because the family size definition could include extended family also, which depends on an individual. Hence, this factor does not depend on other factors directly neither does any of them affect it. Thus, it is seen as an addictive factor.

$$
S \propto \frac{1}{\mathrm{~F}}, S=\frac{K_{4}}{\mathrm{~F}}
$$

\subsubsection{Establishment of Model Parameter Relationships}

From equation (2.5) in the section above,

$$
\text { Let } \quad \mathrm{S}=\frac{\mathrm{K}}{\mathrm{F}} \quad \text { (where } \mathrm{K} \text { is a constant) }
$$

Also in the same vein, we would postulate as follows,

- $\quad$ Let the man's standard of living S; vary jointly as his social status $\mathrm{T}$ and inversely as his spending or expenditure level E, per time. Then Mathematically,

$$
S=\frac{B_{1} T}{E} \quad\left(\text { Where } B_{1} \text { is a constant }\right)
$$

From above, since equation (2.5) is an additive factor, then combining (2.6) and (2.7) gives

$$
\begin{aligned}
& 2 \mathrm{~S}=\frac{\mathrm{K}}{\mathrm{F}}+\frac{\mathrm{B}_{1} \mathrm{~T}}{\mathrm{E}} \\
& \left.\mathrm{S}=\frac{\mathrm{A}}{\mathrm{F}}+\frac{\mathrm{BT}}{\mathrm{E}} \quad \text { (Where: } A=\frac{K}{2}, B=\frac{B_{1}}{2}\right)
\end{aligned}
$$

\subsubsection{Relationship of Other Model Parameters with Income before the Introduction of Government Parameter}

Here we consider $g_{p}=0$ :

By general consideration, since when income I is low with other factors high, the individual's economic standard of living will be low. Implying that, income rate affects all other factors. This means, as $\mathrm{g}_{\mathrm{p}}=0$,

$$
\begin{gathered}
S=K_{I}\left(\frac{A}{F}+\frac{B T}{E}\right) I \\
\therefore S=\frac{\alpha I}{F}+\frac{\beta T I}{E} ; \alpha=A K_{I}, \beta=B K_{I}
\end{gathered}
$$

Where: $\mathrm{E}=$ Expenditure level

$\mathrm{F}=$ Family size

$\mathrm{T}=$ Social status/societal expectations

$\mathrm{I}=$ Income

$\mathrm{g}_{\mathrm{p}}=$ government parameter/fuel subsidy removal effect on income

$\mathrm{S}=$ standard of living, and $\alpha$ and $\beta$ are constants

\subsubsection{Analyzing the Model to Evaluate its Equation \\ Constants}

To evaluate the constants in the model above, equation (2.10) is going to be differentiated partially with respect to $\alpha$ and $\beta$ respectively. To do this, we have to minimize the model using least squares method as follows: From (2.10) we let,

$$
\begin{aligned}
Z_{\min }= & \min \sum\left(S_{i}-\frac{\alpha I_{i}}{F_{i}}-\frac{\beta T_{i} I_{i}}{E_{i}}\right)^{2} \quad \mathrm{i}=1,2,3, \ldots, \mathrm{n} \\
& \frac{\partial Z}{\partial \alpha}=-2 \sum\left(S_{i}-\frac{\alpha I_{i}}{F_{i}}-\frac{\beta T_{i} I_{i}}{E_{i}}\right) \frac{I_{i}}{F_{i}}=0 \\
& \frac{\partial Z}{\partial \beta}=-2 \sum\left(S_{i}-\frac{\alpha I_{i}}{F_{i}}-\frac{\beta T_{i} I_{i}}{E_{i}}\right) \frac{T_{i} I_{i}}{E_{i}}=0 \\
& \therefore \alpha \sum \frac{I_{i}^{2}}{F_{i}^{2}}+\beta \sum \frac{T_{i} I_{i}^{2}}{E_{i} F_{i}}=\sum \frac{S_{i} I_{i}}{F_{i}} \\
& \alpha \sum \frac{T_{i} I_{i}^{2}}{F_{i} E_{i}}+\beta \sum \frac{T_{i}^{2} I_{i}^{2}}{E_{i}^{2}}=\sum \frac{S_{i} T_{i} I_{i}}{E_{i}}
\end{aligned}
$$

$\mathrm{i}=1,2,3 \ldots \mathrm{n}$. But, for this problem $\mathrm{n}=20$. 
Meanwhile Equations (214) and (2.15) are to be solved simultaneously for $\alpha$ and $\beta$.

\subsubsection{Research Instrument Used}

The research instrument used is known as questionnaire. This is because our research is a kind of opinion poll research. However in distributing the questionnaire, only the set of income earners that usually have a clear cut record of their income were considered. This is because; some craftsmen and business persons find it difficult to keep record of the flow of income and that type of data or record may affect the authenticity of our research model.
Also, in the questionnaire there are questions designed to checkmate fake responses. Wherever any element of fake response is discovered, the questionnaire is destroyed accordingly.200 copies of questionnaire were distributed. But only 20 copies which satisfied our acceptability test were considered. We attached a fake response (F.R.)test/ acceptability test to each questionnaire such which any one that became successful was considered for the research.

\subsubsection{Evaluation of the Equation Constants Using the Data Below}

Table 2.1. Questionnaire data for determining our emerging equation constants

\begin{tabular}{|c|c|c|c|c|c|}
\hline Monthly Income (I) & $\begin{array}{c}\text { Government } \\
\text { parameter, } g_{p} \text { as \% } \\
\text { of income }\end{array}$ & Family size (F) & $\begin{array}{c}\text { Expenditure Level(Ex } \\
\text { 0.01) Per Month in } \\
\text { (\%) }\end{array}$ & $\begin{array}{c}\text { Social status/ Societal } \\
\text { Expectation (T x0.01) } \\
\text { in \% }\end{array}$ & $\begin{array}{l}\text { Standard of Living } \\
\text { (S) in \% before } g_{p}\end{array}$ \\
\hline 7000 & 560 & 8 & 0.6 & 0.7 & 40 \\
\hline 17000 & 2040 & 1 & 0.9 & 0.6 & 129 \\
\hline 4500 & 450 & 8 & 0.2 & 0.5 & 52 \\
\hline 8000 & 560 & 3 & 0.6 & 0.6 & 48 \\
\hline 4000 & 360 & 1 & 0.6 & 0.6 & 36 \\
\hline 17500 & 2275 & 9 & 0.4 & 0.6 & 125 \\
\hline 4000 & 300 & 4 & 0.2 & 0.4 & 40 \\
\hline 4700 & 376 & 5 & 0.6 & 0.6 & 25 \\
\hline 8000 & 480 & 2 & 0.4 & 0.6 & 72 \\
\hline 4300 & 387 & 7 & 0.2 & 0.4 & 41 \\
\hline 12000 & 1320 & 5 & 0.8 & 0.7 & 58 \\
\hline 7000 & 490 & 7 & 0.8 & 0.7 & 32 \\
\hline 10500 & 1155 & 3 & 0.6 & 0.6 & 62 \\
\hline 8500 & 765 & 8 & 0.6 & 0.8 & 55 \\
\hline 1500 & 90 & 1 & 0.6 & 0.6 & 14 \\
\hline 2000 & 140 & 1 & 0.4 & 0.5 & 20 \\
\hline 22000 & 1980 & 1 & 0.8 & 0.75 & 94 \\
\hline 4000 & 280 & 3 & 0.4 & 0.4 & 24 \\
\hline 18000 & 1800 & 2 & 0.6 & 0.7 & 135 \\
\hline 4800 & 480 & 2 & 0.8 & 0.6 & 27 \\
\hline
\end{tabular}

Source: Data from the distributed questionnaire

Solving equation (2.14) and (2.15) in the section above simultaneously, where from the table above,

$\sum \frac{T_{i} I_{i}^{2}}{E_{i} F_{i}}=1104306482, \sum \frac{T_{i}^{2} I_{i}^{2}}{E_{i}^{2}}=2685124583$

$\sum \frac{S_{i} T_{i} I_{i}}{E_{i}}=170099.1667, \quad \sum \frac{S_{i} I_{i}}{F_{i}}=$

92305.47619, $\sum \frac{I_{i}^{2}}{F_{i}^{2}}=934161637.5$

Using the data collected,

$\alpha=4.6561047 \times 10^{-5}, \beta=4.4199625 \times 10^{-5}$

$$
S=\frac{4.6561047 \times 10^{-5} I}{F}+\frac{4.4199625 \times 10^{-5} T I}{E}
$$

\subsubsection{Relationship of Other Model Parameters with Income after the Introduction of Government Parameter}

Here we consider $g_{p}=$ fuel subsidy removal financial policy, increase of VAT and others

Basic assumption: By the introduction of government parameter (Removal of fuel subsidy, etc), $\mathrm{g}_{\mathrm{p}}$, it was noticed that $g_{p}$ is a reduction on the human's standard of living. Hence, equation (3.10) above becomes,

$$
S=\frac{\alpha I}{F}+\frac{\beta T I}{E}-\mathrm{g}_{\mathrm{p}}
$$

But

$$
\mathrm{g}_{\mathrm{p}}=\theta \% \text { of } \mathrm{I}=0.01 \times \theta x I ; \quad \text { where } \theta \text { is a }
$$

Using the data collected in table 3.1, 


$$
\theta=\frac{16288}{1713} ; \theta=9.50847
$$

Using equation (2.17) and (2.18) above,

$$
g_{p}=0.09509 \times \mathrm{I}
$$

$$
g_{p} \%=0.0009509 \times \mathrm{I}
$$

By substituting $g_{p}, \alpha$ and $\beta$ into equation (2.17), we have

$$
S=\frac{4.6561047 \times 10^{-5} I}{F}+\frac{4.4199625 \times 10^{-5} T I}{E}-9.50847 \times 10^{-6} \mathrm{I}
$$

or

$$
S=\frac{4.6561047 \times 10^{-5} I}{F}+\frac{4.4199625 \times 10^{-5} T I}{E}-9.50847 \times 10^{-5} \mathrm{~g}_{\mathrm{p}}
$$

The equations (2.16) and (2.21) above are our model equations for the people's standard of living before and after the introduction of government parameter, $\mathrm{g}_{p}$ and they are in a way similar to that of[6]. Although he did not consider government parameter $g_{p}$ and did not formulate his model as explicit as this, nor optimize and supply information about the model's extreme values.

\section{Results and Discussion}

In the concluding part of the previous chapter, data were collected in order to be able to evaluate our emerging model equation constants. Thus, our new model equation now is

$$
S=\frac{\alpha I}{F}+\frac{\beta T I}{E}-9.50847 \times 10^{-6} \mathrm{I}
$$

Where: $\alpha=4.6561047 \times 10^{-5}, \beta=4.4199625 \times 10^{-5}$

But in this chapter, emphasis was laid on analyzing our model by:

1) Optimizing the model

2) Supplying information about the nature of the extreme points of our model

3) Real life interpretation of our optimum values

4) Physical application of our model/ validation of the model

\subsection{Optimization of the Model}

Linear optimization is a mathematical method for determining a way to achieve the best outcome (such as maximum profit or lowest cost) in a given mathematical model, for some lists of requirements represented as linear relationship. And more formally, it is a technique for programming/optimizing an objective function, subject to an inequality or equation constraints. Hence, we wish to optimize our model using Lagrange's Multiplier approach subject to a particular constraint as below.

Optimizing the Model Using Lagrange's Multiplier Subject to $E=184+0.7064 * I$ as Constraint (from analyzed Keynesian Expenditure Theory by [4])
Since from our equation (3.1) above, From our equation (3.1) above,

$$
\begin{gathered}
S=\frac{\alpha I}{F}+\frac{\beta T I}{E}-g_{p} \\
\Rightarrow \quad S=\frac{\alpha I}{F}+\frac{\beta T I}{E}-1 \times 10^{-5} I
\end{gathered}
$$

Setting the constraint equal to zero and multiplying it by our Lagrange multiplier $\lambda$, to get our Lagrange function will give,

$$
S=\frac{\alpha I}{F}+\frac{\beta T I}{E}-1 \times 10^{-5} I+\lambda(E-184-0.7064 I)
$$

Let by supposition the social status of the man $\mathrm{T}$, (at optimal level) $=$ maximum $=100 \%=\frac{100}{100}=1$.

Then, differentiating equation (3.2) partially with respect to $F, E, I$ and $\lambda$ gives

$$
\begin{aligned}
& \frac{\partial S}{\partial F}=\frac{-\alpha I}{F^{2}}=0 \\
& \frac{\partial S}{\partial E}=\frac{-\beta I}{E^{2}}+\lambda=0 \\
& \frac{\partial S}{\partial I}=\frac{\alpha}{F}+\frac{\beta}{E}-0.00001-0.7064 \lambda=0 \\
& \frac{\partial S}{\partial \lambda}=E-184-0.7064 I=0
\end{aligned}
$$

From equation (3.6),

$$
I=\frac{E-184}{0.7064}
$$

Putting (3.7) into (3.3)

$\mathrm{E}=184 \%=1.84$

(This means, at optimal level the man's expenditure level is at the extreme, above $100 \%$ spending)

Thus, by back substitution into (3.7),

$\mathrm{I}=0$ (This means the man's income is of no effect, at optimal level)

To eliminate $\lambda$ in (3.4) and (3.5) above, we perform (3.5) $+(3.4) \times 0.7064$ to give

$$
\begin{gathered}
\frac{-0.7064 \beta I}{E^{2}}+\frac{\alpha}{F}+\frac{\beta}{E}-0.00001=0 \\
\frac{\alpha}{F}=0.00001-\frac{\beta}{1.84}(\text { Since } \mathrm{I}=0 \text { and } \mathrm{E}=1.84) \\
\frac{4.6561047 \times 10^{-5}}{F}=0.00001-\frac{4.4199625 \times 10^{-5}}{184}
\end{gathered}
$$


$\therefore \quad \mathrm{F}=1$ person (this means)

Also, by substituting our values into equation (3.4), $\lambda=0$.

Thus, our critical values are: $\mathrm{E}=184 \%, \mathrm{~F}=1$ person, $\mathrm{T}=$ $100 \%, \lambda=0$ and $\mathrm{I}=0$ as $\mathrm{E}$ tends to maximum

This implies that,

Standard of living of the man, $\mathrm{S} \rightarrow 0$ as his expenditure level $\mathrm{E} \rightarrow \infty$

And this in real life means that the man's Standard of living tends to $0 \%$ as his expenditure level, $\mathrm{E}$ is geometrically or infinitely rising. If he keeps spending high, his Standard of living will tends to $0 \%$

\subsection{Observation on the Nature of the Models' Extreme Values}

This stage is necessary in order to know whether the model's extreme point is a minimum or a maximum.

Generally, given a function $\mathrm{f}(\mathrm{x}, \mathrm{y})$ that obeys the continuity of the partial derivatives and we

Let: $A=\frac{\partial^{2} f}{\partial x^{2}}, \mathrm{~B}=\frac{\partial^{2} \mathrm{f}}{\partial x \partial y}, \mathrm{C}=\frac{\partial^{2} \mathrm{f}}{\partial y^{2}}$ then,

1) If $\mathrm{B}^{2}-\mathrm{AC}<0$, then $\mathrm{f}(\mathrm{x}, \mathrm{y})$ has extreme value at $\left(\mathrm{x}_{0}\right.$, $\mathrm{y}_{\mathrm{o}}$ ) and minimum if $\mathrm{A}>0$ and it is maximum if $\mathrm{A}<$ 0

2) IfB $^{2}-\mathrm{AC}>0$, or $\mathrm{AC}<\mathrm{B}^{2}$ then $\mathrm{f}(\mathrm{x}, \mathrm{y})$ has no extreme value. That is, it has a saddle point at $\left(\mathrm{x}_{\mathrm{o}}\right.$, $\mathrm{y}_{\mathrm{o}}$ ).

3) If $\mathrm{B}^{2}-\mathrm{AC}=0$, then no information is derivable about its extreme values.

Similarly, from our reduced model equation variables,

$$
S=\left(\frac{\alpha}{F}+\frac{\beta}{E}-0.00001\right) I ;
$$

but,

$$
\begin{gathered}
I=\frac{E}{0.7064}-\frac{184}{0.7064}, \text { from }(4.7) \& \text { our constraint equ. } \therefore \\
S=\left(\frac{\alpha}{F}+\frac{\beta}{E}-0.00001\right)\left(\frac{E}{0.7064}-\frac{184}{0.7064}\right)
\end{gathered}
$$

And

$$
\begin{gathered}
\frac{\partial S}{\partial F}=\frac{-\alpha}{F^{2}}\left(\frac{E}{0.7064}-\frac{184}{0.7064}\right) \\
\frac{\partial S}{\partial E}=\frac{-\beta}{E^{2}}\left(\frac{E}{0.7064}-\frac{184}{0.7064}\right)+\frac{1}{0.7064}\left(\frac{\alpha}{F}+\frac{\beta}{E}-0.00001\right) \\
=\left(\frac{-\beta}{0.7064 E}+\frac{184 \beta}{0.7064 E^{2}}\right)+\left(\frac{1.4156 \alpha}{F}+\frac{1.4156 \beta}{E}-0.00001416\right) \\
\therefore \frac{\partial^{2} S}{\partial F^{2}}=\frac{2 \alpha}{F^{3}}\left(\frac{E}{0.7064}-\frac{184}{0.7064}\right), \\
\left.\frac{\partial^{2} S}{\partial F^{2}}\right|_{E=184}=0,(\text { by substituting our critical values })
\end{gathered}
$$

$$
\begin{gathered}
\frac{\partial^{2} S}{\partial E^{2}}=\left(\frac{\beta}{0.7064 E^{2}}-\frac{520.98 \beta}{E^{3}}-\frac{1.4156 \beta}{E^{2}}\right) \\
\therefore \frac{\partial^{2} S}{\partial E^{2}}=\frac{0.00002016 \beta}{0.7064 E^{2}}-\frac{520.98 \beta}{E^{3}} \\
\frac{\partial^{2} S}{\partial F \partial E}=\frac{\partial}{\partial F}\left(\frac{\partial S}{\partial E}\right)=\frac{-\alpha}{F^{2}}\left(\frac{1}{0.7064}\right) \\
\text { If }, \frac{\partial^{2} S}{\partial E^{2}}=A, \frac{\partial^{2} S}{\partial F \partial E}=B \text { and } \frac{\partial^{2} S}{\partial F^{2}}=C,
\end{gathered}
$$

Then, by substituting our critical values,

$$
B^{2}-A C=\left(\frac{-4.6561047 \times 10^{-5}}{1}\right)^{2}\left(\frac{1}{0.7064}\right)^{2}-0>0
$$

Hence, $\mathrm{B}^{2}-\mathrm{AC}>0$

(It means $\mathrm{S}$ has a Saddle-point and has no local extremum or it has no specific optimal value)

\subsection{Real Life Interpretation/Implication of the Model's Optimal/ Extreme Values}

From our calculated values at optimal level, $\mathrm{E}=184 \%, \mathrm{~F}$ $=1$ person, $\mathrm{T}=100 \%, \mathrm{I} \rightarrow 0$.

The physical implication of these values is that:

Family size $(\mathrm{F})$ : for this value to be $\mathrm{F}=1$ person, it means the man cannot fend for any other person no matter how small except himself at optimal level. This Implies also that such a man cannot get married not to talk of having a child and still have economic comfort because of the state of his critical standard of living.

Expenditure level (E): it was indicated that at optimal level, the man has above $100 \%$ spending rate. This actually accounts for the poor standard of living because his expenditure level is geometrically increasing; any income that comes in goes out.

Income (I): for this value that says, $\mathrm{I} \rightarrow 0$, we observe also that at optimal level, the man's income tends to have no effect. This is for the same reason above that, any income that comes in, goes out because of the man's expenditure level at the peak as $184 \%$.

Societal expectation/social status (T): since the man's societal expectation is highest at optimal level, then this also accounts for high expenditure level, which consequently leads to a poor standard of living at large.

Government Parameter $\left(g_{p}\right)$ : since we can express this parameter in terms of the man's income at optimal level, then we can say this value and the man's per capital income (I) is the major reason for his poor standard of living at optimal level.

\subsection{Validation of the Model}

The model was validated using direct substitution of the questionnaire data in table2.1 above into the model equations (2.16) and (2.21) which are the standard of living 
model for before and after the introduction of government parameter. These two model results were compared in the next section.

\subsubsection{Comparison between the Nigerians'Standard of Living before and after Introduction of $g_{p}$ along with Standard of Living Value \& Questionnaire Comparison}

In this section, we compared our model Standard of Living values for before and after the introduction of government parameter, $\mathrm{g}_{\mathrm{p}}$. Likewise, we compared our model results for Nigerians' Standard of Living before the Introduction of $g_{p}$ with the questionnaire data gathered for the research in table 2.1 .

Table 3.1. Tabular Comparison between the Nigerian's Standard of Living before And After Introduction of $g_{p}$

\begin{tabular}{cccc}
\hline People Involved & $\begin{array}{c}\text { STANDARD OF LIVING (\%) (Before } \\
\left.\text { Introduction of } \mathbf{g}_{\mathrm{p}}\right)\end{array}$ & $\begin{array}{c}\text { STANDARD OF LIVING (\%) (After } \\
\text { Introduction of } \mathbf{g}_{\mathrm{p}} \text { ) }\end{array}$ & $\begin{array}{c}\text { Differences (Absolute) } \\
\text { in \% }\end{array}$ \\
\hline Person A & 47.78 & 40.14 & $7.64 \%$ \\
Person B & 25.15 & 20.1 & $5.05 \%$ \\
Person C & 32 & 25.1 & $6.9 \%$ \\
Person D & 20 & 14.4 & $5.6 \%$ \\
Person E & 27.1 & $5 \%$ & 22 \\
\hline
\end{tabular}

Table 3.2. Comparison between the Model data for standard of Living \&our Questionnaire

\begin{tabular}{cccc}
\hline People involved & $\begin{array}{c}\text { Standard of living (\%) (calculated by our } \\
\text { model) }\end{array}$ & $\begin{array}{c}\text { Standard of living (\%) (questionnaire } \\
\text { data) }\end{array}$ & $\begin{array}{c}\text { Error (absolute) } \\
\text { Person A }\end{array}$ \\
\hline Person B & 47.78 & 48 & 25 \\
Person C & 25.15 & 32 & $0.22 \%$ \\
Person D & 31.73 & 20 & $0.15 \%$ \\
Person E & 20.36 & $27 \%$ & $0.36 \%$ \\
\hline
\end{tabular}

\section{Remark}

Table 3.1 and 3.2 above shows the validation of randomly $4^{\text {th }}, 8^{\text {th }}, 12^{\text {th }}, 16^{\text {th }}$ and the $20^{\text {th }}$ record of our questionnaire data in table 2.1 and the absolute error respectively.

The analysis of the result in table 3.1 shows that the error between our calculated model data for before and after the introduction of government parameter in most cases, is approximately $10 \%$ (to the nearest tens) which confirms the fact that any sudden government financial policy takes/reduces approximately $10 \%$ of the citizen's standard of living and income status.

\subsection{Discussion of Results}

The outcome of our comparison between Nigerians' standard of living before and after the introduction of government policy parameter $g_{p}$ in equation (2.19) and table 3.1 , reveals that financial related policies in the country takes/reduce approximately $10 \%$ of the citizens' economic comfort and income. Similarly, Table 3.2 on the other hand shows that the differences between our calculated model data and the questionnaire data in all the cases considered was not up to $1 \%$. And moreso, the absolute error between the model results and our raw questionnaire data using our model equation (2.16) indicates a value approximately +0.7 ranking correlation coefficient which therefore recommends the model as a standard measure for estimating the effect of government parameter on the citizen's standard of living.
Equally, from our optimization result in equation (3.8) above, it was noticed at various levels of our model analysis that there is no particular level of standard of living of a man/household which can be called the maximum or minimum standard of living. This is consequent upon obtaining "Saddle-point" as the model's extreme/optimal value. Thus, no value of a person's economic standard is critical enough to momentarily stop his existence. This then implies that human beings can exist even at critical level of standard of living that is close to zero percent. Hence, the proportion of the population that has critical standard of living who will not die until help comes their way through the country's poverty alleviation programmes or they seek for help themselves either through positive or negative means, constitutes the main factor for much security threats in the country.

\section{Conclusion}

Since, the model has spotted that most situations of unrest, insecurity and other social vices in any country (Nigeria inclusive) is caused by the inability of the government to make backup plans to cushion the effect of any financial related policy made in relation to the citizen's standard of living, then it is time for our governments and other non-governmental agencies to rise to their responsibilities in this regard. Any decision or activity contrary to this is anti-developmental agenda of any country. And it is another way of saying the economic vision of that country cannot be achieved at the time 
speculated. More so, as Nigeria is in a hurry to obtain economic stability between now and the year 2020, this research is therefore timely and the utilization of all its specifications alike.

\section{References}

[1] Adeboye, K. R., Lecture notes on Introduction to Mathematical Modelling, Mathematics and Computer Science Department, Federal University of Technology, Minna, Nigeria, pp1-end, (2006).

[2] Aganbegian, A. \& Rimashevskaia, N., Application of Mathematical Models and Electronic Computers in Economic Calculations of Workers' Wage Scales, Income and Consumption, A SpringerLink - Journal Article, 4(5) (2006), 1-6.

[3] Dogo, J. D., The Role of Mathematics in National Building Forum Academics, A multi-Disciplinary Journal of Education, 1(1) (1998), pp.18.

[4] Javitz, H., Grimes T., Hill D., Rapoport A., Bell R., Fecso R., Lehming R.,US Academic Scientific Publishing Working papers SRS11 /201. Arlington, VA: National Science foundation, Division of Science Resources Statistics, (2010),www.cces.fudan.edu.cn-CH1.pdf
[5] MAC Participant Manual; Debate to Action MDGs Awareness Campaign-National Youth Service Corps, British Council \& World Bank Institute Collaboration on Development Issues Manual (Development Knowledge Facilitators Course Materials for Development in My Community), Community Development Service project, Nigeria,pp.7, (2006).

[6] Negedu, D. Mathematical Model for Human Standard of living; B.Sc Research work, submitted to Mathematics and Computer Science Department, Federal University of Technology, Minna, Niger State, Nigeria, pp1-end.(2010).

[7] NV 20-2020 Economic Transformation Blueprint; Nigeria Vision 20: 2020 Economic Transformation Blueprint; October, 2009 Edition, pp7, (2009).

[8] Ogwumu O.D.,Adeboye K.R., Emesowum C.E., Adeyefa E.O., Mathematical Model for Estimating the Standard of Living of Nigerians and Achieving the First Agenda of the Vision 20; 2020, International Journal of Science Technology and Education (Mathematical theory and Modelling) ISSN2225-0522, 3(8)(2013) pp. 90-96.

[9] Raymond, C. Standard of Living Publication, (2011). www.hubpages.com / UnitedStatesPoliticalandSocial Issues.

[10] Yemi,F., The Nigerian Poverty Profile 2011 Report: Press briefing by the Nigerian Statistician General of the Federation. (2012), www.nigeriadailynews.com/general/29... 